\title{
EDUCAÇÃO INCLUSIVA E RESPONSABILIDADE SOCIAL
}

\section{ARTIGO ORIGINAL}

AMARAL, Renilda Gonçalves do ${ }^{1}$

OLIVEIRA, Rita Barreto de Sales²

AMARAL, Renilda Gonçalves do. OLIVEIRA, Rita Barreto de Sales. Educação inclusiva e responsabilidade social. Revista Científica Multidisciplinar Núcleo do Conhecimento. Ano 04, Ed. 04, Vol. 05, pp. 85-103 Abril. de 2019. ISSN: 2448-0959

\section{RESUMO}

Este artigo tem como propósito analisar a inclusão de pessoas com necessidades especiais no sistema escolar. Por meio de pesquisa bibliográfica, fez-se uma síntese da história da inclusão de pessoas com necessidades especiais em idade escolar e apresentaram-se documentos relevantes que impulsionaram a inclusão social de indivíduos com deficiências. Ademais, questionou-se a responsabilidade do Estado pelo atendimento deficitário da comunidade escolar que necessita de cuidados especiais na escola da rede pública de Ensino do Distrito Federal.

${ }^{1}$ Professora da Secretaria de Estado de Educação do Distrito Federal. Doutora em Ciência da Informação pela Universidade de Brasília (2013). Mestre em Ciência da Informação pela Universidade de Brasília - UnB (2008). Especialista em Moderna Literatura Brasileira pelo Centro de Ensino Unificado de Brasília. Licenciada em Letras pela Universidade de Brasília - UnB (1979).

2 Professora da Secretaria de Estado de Educação do Distrito Federal. Doutora em Ciências da Educação pela Universidad Americana - PY (2014). Mestre em Ciência da Informação pela Universidade de Brasília - UnB (2008). Licenciada em Letras pelo Centro de Ensino Unificado de Brasília (1984). Aluna do Programa de PósDoutoramento da Universidad Iberoamericana de Asunción - PY em parceria com o Instituto IDEIA-BR. 
Palavras-Chave: Educação especial, Necessidades especiais, Atendimento deficitário, Responsabilidade do Estado.

\section{INTRODUÇÃO}

A história registra o percurso realizado por indivíduos com necessidades especiais para se adaptarem e se integrarem ao cotidiano. Amaral (1997) revela que a marginalização de pessoas com deficiência não é tema contemporâneo, mas se encontra presente em todas as sociedades da Antiguidade Clássica aos dias atuais. É fato que, a partir de 1990, ocorreram propostas explícitas, emanadas do poder público e da legislação, para a educação, as quais reforçam o direito dos alunos com necessidades especiais de serem atendidos nas salas comuns do ensino regular. Assim, pode-se compreender que a escola é o ambiente formador por excelência do ser social; devendo estar aparelhada para recepcionar indivíduos, com suas peculiaridades, independente de um padrão de normalidade, das séries iniciais ao ensino superior.

\section{A EDUCAÇÃO INCLUSIVA E A LEGISLAÇÃO}

Um dos mais belos discursos sobre a educação foi pronunciado por Kofi Annan (1998) apud Oliveira (2014). Neste ele afirmou:

A educação é um direito humano com uma imensa potencialidade de produzir mudança. $\mathrm{Na}$ sua base residem as pedras angulares da liberdade, democracia e desenvolvimento sustentável... Não existe maior prioridade, missão mais importante, do que a Educação para Todos.

Em nossa Carta Magna, título VIII, da Ordem Social, capítulo III, Seção I, art. 205, está prescrito que

a educação, direito de todos e dever do Estado e da família, será promovida e incentivada com a colaboração da sociedade, visando ao 
pleno desenvolvimento da pessoa, seu preparo para o exercício da cidadania e sua qualificação para o trabalho.

Dessa forma, a Lei determina que todo cidadão brasileiro tem direito à educação e o Estado e a família são corresponsáveis sociais, ao tempo em que objetiva o desenvolvimento integral do educando como cidadão e futuro profissional. O texto da Carta Magna reitera: "cabe o dever principal ao Estado, representado pela União, Estados, Distrito Federal e Municípios".

Ainda o artigo 208, III, do mesmo título, garante o "atendimento educacional especializado aos portadores de deficiência, preferencialmente na rede regular de ensino". Este artigo registra que

a Lei no 7.853, de 24-10-1989, regulamentada pelo Decreto no 3.298, de 20-12-1999, consolida as normas de proteção à pessoa portadora de deficiência; a Lei o 10.845, de 5-3-2004, institui o Programa de Complementação ao Atendimento Educacional Especializado às Pessoas Portadoras de Deficiência; a Lei no 13.146, de 6-7-2015, institui o Estatuto da Pessoa com Deficiência.

Outros documentos corroboram para que sujeitos estigmatizados por desigualdades sociais não sofram exclusão dentro e fora da escola, quer sejam a Lei oํ 10.172/01 que aprova o Plano Nacional de Educação; a Lei o 853/89 que dispõe sobre o apoio às pessoas com deficiência, sua integração social; a Lei no 8069/90 que dispõe sobre o Estatuto da Criança e do Adolescente; a Lei no 9.394/96 que estabelece as diretrizes e bases da educação nacional; a Portaria do MEC nº 679/99 e a Lei № 10.098/00. Mais recentemente é criado o Estatuto da Pessoa com Deficiência no 13.1146/2015, o qual se propõe a assegurar e promover o exercício de direitos e liberdades fundamentais de indivíduos com necessidades especiais para que tenham condições iguais aos demais cidadãos.

Pelo exposto, percebe-se que a legislação brasileira tem se posicionado incisivamente sobre a questão: alunos com necessidades especiais não devem ser encaminhados 
a salas especiais, mas, de preferência, incluídos em classes comuns nas escolas, salvo exceções. Como se vê, o direito ao atendimento e à qualidade do Ensino configura-se explícito em um rol de documentos oficiais.

Além do mais, ao tomar uma posição político-filosófica de cunho internacional, o Brasil concordou com a Declaração Mundial de Educação para Todos, assinada em Jomtien, na Tailândia (1990) e com a Conferência Mundial sobre Necessidades Educacionais Especiais realizada na Espanha em 1994, onde se produziu um documento em que a nação brasileira se posicionou favorável, de cujo teor pode-se ressaltar que "as pessoas com necessidades especiais devem ter acesso às escolas comuns que deverão integrá-las numa pedagogia centralizada na criança, capaz de atender a essas necessidades" (ARANHA, 2004, p. 17).

\section{DISCUSSÃO}

A Constituição Federal (1988) determina a matrícula de todos os alunos, quer sejam especiais ou não, e o não cumprimento do dispositivo pode ter como consequência a punição, conforme preconiza o artigo 8º $^{\circ}$ da Lei no $7.853 / 89$ :

constitui crime, punido com reclusão, recusar, suspender, procrastinar, cancelar ou fazer cessar, sem justa causa, a inscrição de aluno em estabelecimento de ensino, de qualquer curso ou grau, público ou privado, por motivos derivados da deficiência que porta.

Já o Artigo 2º, da Resolução CNE/CEB ํo 2, de 11 de setembro de 2001 também enfatiza:

Os sistemas de ensino devem matricular todos os alunos, cabendo às escolas organizar-se para 0 atendimento aos educandos com necessidades educacionais especiais, assegurando as condições necessárias para uma educação de qualidade para todos. 
$\mathrm{Na}$ prática, percebe-se que a escola pública do DF se organiza, dentro de suas possibilidades, para recepcionar o aluno com necessidades especiais, no entanto, é refém da burocracia do sistema. $\mathrm{O}$ artigo 12 dessa Resolução ressalta:

Os sistemas de ensino, nos termos da Lei 10.098/2000 e da Lei 10.172/2001, devem assegurar a acessibilidade aos alunos que apresentem necessidades educacionais especiais, e a eliminação de barreiras arquitetônicas urbanísticas, na edificação - incluindo instalações, equipamentos e mobiliário - e nos transportes escolares, bem como de barreiras nas comunicações, provendo as escolas dos recursos humanos e materiais necessários.

Apesar disso, a rotina, a vivência, na escola pública do DF demonstra que a escola está distante de seu ideal, submetendo seus alunos a situações inusitadas, às vezes, não oferecendo o mínimo conforto, até mesmo para suas necessidades orgânicas mais prementes.

Corroborando com o exposto acima Campos (2017) afirma que a Secretaria de Educação foi advertida para melhorar imediatamente a estrutura de Centros de Educação Especial - CEEs no Distrito Federal, uma vez que uma Auditoria do Ministério Público de Contas - MPC identificou que as unidades do Gama, Guará, Planaltina e Sobradinho necessitam fazer reparos na rede elétrica, nos reservatórios de água e em piso para quadra de esportes, além de contratar pessoal e até remover edificações irregulares erguidas nos terrenos das unidades.

Esse autor afirma que os problemas nos centros de ensino são vários. Porém, deveriam ser maiores, segundo o relatório produzido pelos auditores, se não fosse o esforço da comunidade escolar em concretizar os reparos por conta própria. A rede pública de ensino do DF conta atualmente com 13 centros de ensino especial e 2.339 alunos.

O autor supracitado cita como exemplo o Centro de Ensino Especial 1 do Guará CEE 1 do Guará, no qual os auditores denunciaram uma falha grave no reservatório 
de água. Segundo o relatório dos mesmos, a "corrosão verificada pode ocasionar a queda do equipamento (caixa d'água)", causando um acidente, pois o reservatório fica perto das salas de aula. E acrescenta que em 2011, a direção da escola fez o pedido do reparo na caixa d'água e ganhou, cinco anos depois do pedido e ainda como solução paliativa, um novo reservatório de cinco mil litros.

Magalhães e Lima (2004) garantem que as experiências e pesquisas científicas que dizem respeito à inclusão de alunos com necessidades especiais na escola regular enfatizam a inexistência de modelos predeterminados para a criação de sistemas de ensino inclusivos e que, de modo efetivo, as escolas inclusivas têm como eixos norteadores as flexibilizações de currículos e metodologias, com o objetivo de lidar, de modo criativo, com as diferenças individuais expostas por esses alunos.

Outra questão a considerar é a constatação de que algumas escolas públicas foram construídas para atender alunos do Ensino Fundamental Fase I (alunos do $1^{\circ}$ ao $5^{\circ}$ ano), entretanto, recebem alunos da Fase II (do 6 ao 9a anos), isto é, não possuem estrutura física adequada. Educandos praticam educação física em área exposta, fora do ambiente escolar, em quadra pública, sem proteção alguma. Pergunta-se se esta escola pública está preparada para atender também alunos com necessidades especiais que demandam maiores especificidades e exigências para a viabilização da educação inclusiva.

O artigo 8을 da Resolução CNE/CEB nํ2, de 11 de setembro de 2001, registra que

(...) as escolas da rede regular de ensino devem prever e prover na organização de suas classes comuns: I - professores das classes comuns e da educação especial capacitados e especializados, respectivamente, para 0 atendimento às necessidades educacionais dos alunos; (...) IV - serviços de apoio pedagógico especializado em salas de recursos, nas quais o professor especializado em educação especial realize a complementação ou suplementação curricular, utilizando procedimentos, equipamentos e materiais específicos. 
Ora, a escola pública, mediante estratégia de matrícula, prevê, para compor suas classes comuns, professores para atendê-las, bem como à educação especial; monitores e outros serviços de apoio pedagógico, porém a provisão é feita exclusivamente pelo Setor de Movimentação de Pessoal, o qual se responsabiliza pela seleção e encaminhamento destes profissionais para a escola. No entanto, a escola pública, em sua rotina, sofre alterações quando estes profissionais se ausentam por motivos variados, seja por licença médica, licença prêmio, aposentadorias, abonos, e outros direitos, situação que ocorre com frequência. A solicitação para substituir o profissional ausente é realizada imediatamente, porém a burocracia impede que a movimentação/substituição de professores e monitores seja realizada a contento; há profissionais que se apresentam na escola após 30 dias ou mais da solicitação. Dessa forma, há um lapso de tempo expressivo entre as aposentadorias e licenças e a consequente convocação de profissional substituto conveniente o que obriga a escola muitas vezes a recorrer a outros profissionais de outros setores (coordenadores, orientadores, professores bibliotecários) para não deixar o aluno com necessidade especial sem atendimento.

Nesse passo, aparece a figura do Educador Social, indivíduo voluntário, o qual, pelo programa, tem direito a $R \$ 25,00$ diários para despesas de transporte e alimentação; tal programa objetiva assessorar e ampliar as atividades de educação integral e educação especial. Estes voluntários devem ter idade mínima de 18 anos para atuarem em atendimento educacional especializado; podem ser estudantes de Ensino Médio, EJA - Educação de Jovens e Adultos e universitários como também pessoas da comunidade com habilidades em atividades culturais, artísticas, desportivas, ambientais, culinárias. Os voluntários deverão atuar sob orientação e supervisão do profissional da sala de recursos, supervisor pedagógico ou coordenador pedagógico das escolas. Assim, muitas vezes, também para suprir a demanda, estes voluntários são alocados para ficar com alunos especiais na ausência do profissional da sala de recursos. Questiona-se se, segundo as Diretrizes Nacionais para Educação Especial na Educação Básica (2001) para dar "sustentação ao processo de construção da educação inclusiva" (p. 69) não haveria de se ter "serviços de apoio pedagógico especializado em salas de recursos" (p. 72)? 
Outra questão a ser verificada é a permanência domiciliar de determinados alunos especiais, quando seus professores, por licenças várias, estão impossibilitados de ministrar aulas ou de acompanhá-los; alguns alunos permanecem em casa por mais de 15 dias por falta de substituição imediata. Assim, como entender o processo de construção da inclusão se não houver sequenciamento do ensino? Segundo Mendes (2006, p. 12),

tal quadro indica muito mais uma exclusão escolar generalizada dos indivíduos com necessidades especiais na realidade brasileira, a despeito da recorrência no país da retórica da integração e mais recentemente da educação inclusiva.

Pode-se, ainda, fazer referência à extrema mobilidade de professores que não se adaptam ao Ensino Especial, sabe-se constar da Resolução CNE/CEB ํㅜㄹ, de 11 de setembro de 2001, Art. 18, que

cabe aos sistemas de ensino estabelecer normas para o funcionamento de suas escolas, a fim de que essas tenham as suficientes condições para elaborar seu projeto pedagógico e possam contar com professores capacitados e especializados, conforme previsto no Artigo 59 da LDBEN e com base nas Diretrizes Curriculares Nacionais para a Formação de Docentes da Educação (...).

O Artigo 18 enfatiza ainda no $\S 1^{\circ}$ que

são considerados professores capacitados para atuar em classes comuns com alunos que apresentam necessidades educacionais especiais, aqueles que comprovem que, em sua formação, de nível médio ou superior, foram incluídos conteúdos sobre educação especial adequados ao desenvolvimento de competências e valores.

Assim, o que se levanta nesse âmbito é a necessidade de formação continuada para os profissionais ligados direta e indiretamente às atividades dos alunos com 
necessidades especiais. Importante ainda refletir se as políticas públicas remetem à política de atendimento ou de serviços prestados.

Nessa linha de entendimento, são verificados no documento Política Nacional de Educação Especial na Perspectiva da Educação Inclusiva (BRASIL, 2008) os marcos históricos e normativos referentes à educação especial no Brasil, os quais são:

1) Inauguração, na época do Império, de duas instituições: o Imperial Instituto dos Meninos Cegos, em 1854, atualmente conhecido como Instituto Benjamin Constant IBC; e o Instituto dos Surdos Mudos, em 1857, hoje denominado de Instituto Nacional da Educação dos Surdos - INES. Ambos ficam no Rio de Janeiro.

2) A implantação do Instituto Pestalozzi, instituição especializada no atendimento às pessoas com deficiência mental, em 1926.

3) A inauguração da primeira Associação de Pais e Amigos dos Excepcionais - APAE, em 1954.

4) $O$ estabelecimento do primeiro atendimento educacional especializado às pessoas com superdotação na Sociedade Pestalozzi, por Helena Antipoff, em 1954.

5) Em 1961, a promulgação da Lei ํo 4.024/61, a qual garante aos excepcionais a educação, de preferência no sistema geral de ensino.

6) A Lei ํㅜ 5.692/71, que alterou a LDBEN de 1961, ao definir "tratamento especial" para os alunos com "deficiências físicas, mentais, os que se encontram em atraso considerável quanto à idade regular de matrícula e os superdotados", não conseguindo dar impulso à organização de um sistema de ensino com capacidade para atender as necessidades educacionais especiais, termina fortalecendo o encaminhamento dos alunos para as classes e escolas especiais.

7) Em 1973, o Ministério da Educação - MEC, fundou o Centro Nacional de Educação Especial - CENESP, encarregado de gerenciar a educação especial no Brasil, que impulsionou ações educacionais dirigidas às pessoas com deficiência e às pessoas 
com superdotação, mesmo configuradas por campanhas assistenciais e iniciativas isoladas do Estado. Nessa época, permaneceu a concepção de políticas especiais para tratar da educação de alunos com deficiência. E quanto aos alunos com superdotação, mesmo que tivessem acesso ao ensino regular, não foi organizado um atendimento especializado que levasse em consideração as suas singularidades de aprendizagem.

8) A Constituição Federal de 1988, em seu artigo 208, garante, como dever do Estado, a oferta do atendimento educacional especializado, preferencialmente na rede regular de ensino, conforme já foi visto anteriormente.

9) O Estatuto da Criança e do Adolescente - ECA, Lei oㅡ 8.069/90, em seu artigo 55, apresentou um reforço aos dispositivos legais supracitados ao determinar que os pais ou responsáveis tinham a obrigação de matricular seus filhos na rede regular de ensino. Foi também nesse período que documentos como a Declaração Mundial de Educação para Todos (1990) e a Declaração de Salamanca (1994) começaram a influenciar a formulação das políticas públicas da educação inclusiva.

10) Em 1994, foi publicada a Política Nacional de Educação Especial, direcionando o processo de "integração instrucional", a qual condicionava o acesso às classes comuns do ensino regular aos que tivessem condições de acompanhar e desenvolver as atividades curriculares programadas do ensino comum, no mesmo compasso que os alunos ditos normais. Dessa forma, reafirmou os pressupostos construídos a partir de padrões homogêneos de participação e aprendizagem, não gerando uma reformulação das práticas educacionais, de modo que houvesse uma valorização dos diferentes potenciais de aprendizagem no ensino comum, embora mantivesse a responsabilidade da educação dos portadores de necessidades educacionais especiais exclusivamente no âmbito da educação especial.

11) A atual Lei de Diretrizes e Bases da Educação Nacional, Lei no 9.394/96, no artigo 59, dispõe que os sistemas de ensino devem garantir aos alunos currículo, métodos, recursos e organização específicos para atender às suas necessidades. Assegura também a terminalidade específica aos que não atingiram o nível exigido para a 
conclusão do Ensino Fundamental, em virtude de suas deficiências, e garante a aceleração de estudos aos superdotados para conclusão do programa escolar. Determina, ainda, como normas para a organização da educação básica, a possibilidade de avanço nos cursos e nas séries, conforme verificação do aprendizado, e oportunidades educacionais apropriadas, considerando-se as características do alunado, seus interesses, condições de vida e de trabalho, por meio de cursos e exames.

12) Em 1999, o Decreto $n^{0} 3.298$, o qual regulamenta a Lei $n=7.853 / 89$, demarca a educação especial como uma modalidade transversal a todos os níveis e modalidades de ensino, dando destaque à atuação complementar da educação especial ao ensino regular.

13) As Diretrizes Nacionais para a Educação Especial na Educação Básica, na Resolução CNE/CEB ํo 2/2001, no artigo 2ํ, deliberam que os sistemas de ensino matriculem todos os alunos, deixando às escolas a organização para o atendimento aos educandos com necessidades educacionais especiais, garantindo as condições necessárias para uma educação de qualidade para todos.

14) O Plano Nacional de Educação - PNE, Lei no $10.172 / 2001$, determina objetivos e metas para que os sistemas de ensino favoreçam o atendimento às necessidades educacionais especiais dos alunos, acusando um déficit referente à oferta de matrículas para alunos com deficiência nas classes comuns do ensino regular, à formação docente, à acessibilidade física e ao atendimento educacional especializado.

15) A Convenção da Guatemala de 1999, promulgada no Brasil pelo Decreto no 3.956/2001, afirma que as pessoas com deficiência têm os mesmos direitos humanos e liberdades fundamentais que as demais pessoas, definindo como discriminação com fundamento na deficiência toda diferenciação ou exclusão capaz de anular o exercício dos direitos humanos e de suas liberdades fundamentais. 
16) A Lei oํ 10.436/02 adota a Língua Brasileira de Sinais - Libras, como meio legal de comunicação e expressão, determinando que sejam garantidas formas institucionalizadas de apoiar seu uso e difusão, assim como a inclusão da disciplina de Libras como parte integrante do currículo nos cursos de formação de professores e de fonoaudiologia.

17) A Portaria $n^{\circ} 2.678 / 02$ do MEC aprova diretrizes e normas para o uso, o ensino, a produção e a difusão do sistema Braille em todas as modalidades de ensino, dando configuração ao projeto da Grafia Braille para a Língua Portuguesa e a recomendação para o seu uso em todo o território nacional.

18) Em 2003, é implementado pelo MEC o Programa Educação Inclusiva: Direito à Diversidade, com o intuito de apoio à transformação dos sistemas de ensino em sistemas educacionais inclusivos, o qual gerou um amplo processo de formação de gestores e educadores nos municípios brasileiros, assegurando o direito de acesso de todos à escolarização, à oferta do atendimento educacional especializado e à garantia à acessibilidade.

19) Em 2004, o Ministério Público Federal divulga o documento $O$ Acesso de Alunos com Deficiência às Escolas e Classes Comuns da Rede Regular, objetivando a disseminação dos conceitos e diretrizes mundiais para a inclusão, confirmando o direito e os benefícios da escolarização de alunos com e sem deficiência nas turmas comuns do ensino regular.

20) O Decreto № 5.296/04 regulamentou as Leis $n^{\circ}$ 10.048/00 e $n^{0}$ 10.098/00, decretando normas e critérios para a promoção da acessibilidade às pessoas com deficiência ou com mobilidade reduzida. Nesse contexto, o Programa Brasil Acessível, do Ministério das Cidades, foi desenvolvido com o intuito de promoção da acessibilidade urbana e apoio a ações que assegurem o acesso universal aos espaços públicos.

21) O Decreto $n^{\circ} 5.626 / 05$, que regulamenta a Lei $n^{0}$ 10.436/2002, com o intuito de dar acesso à escola dos alunos surdos, regulamenta a inclusão da Libras como 
disciplina curricular, a formação e a certificação de professor, instrutor e tradutor/intérprete de Libras, o ensino da Língua Portuguesa como segunda língua para alunos surdos, bem como a organização da educação bilíngue no ensino regular.

22) Em 2005, são inaugurados os Núcleos de Atividades de Altas Habilidades/Superdotação - NAAH/S em todos os estados e no Distrito Federal. Organizam-se centros de referência na área das altas habilidades/superdotação para o atendimento educacional especializado, para a orientação às famílias e a formação continuada dos professores; constitui-se a organização da política de educação inclusiva de maneira a garantir esse atendimento aos alunos da rede pública de ensino.

23) A Convenção sobre os Direitos das Pessoas com Deficiência, confirmada pela Organização das Nações Unidas - ONU em 2006 e da qual o Brasil é signatária, propõe que os Estados-Partes devem garantir um sistema de educação inclusiva em todos os níveis de ensino, em ambientes que maximizem o desenvolvimento acadêmico e social compatível com a meta da plena participação e inclusão, adotando medidas para garantir: a) A não exclusão das pessoas do sistema educacional geral sob alegação de deficiência, assim como a não exclusão de crianças com deficiência do Ensino Fundamental gratuito e compulsório, sob alegação de deficiência; b) $\mathrm{O}$ acesso das pessoas com deficiência ao Ensino Fundamental inclusivo, de qualidade e gratuito, em igualdade de condições com as demais pessoas na comunidade em que vivem (Art. 24).

24) Ainda em 2006, a Secretaria Especial dos Direitos Humanos, os Ministérios da Educação e da Justiça, em conjunto com a Organização das Nações Unidas para a Educação, a Ciência e a Cultura - UNESCO, difundem o Plano Nacional de Educação em Direitos Humanos, que tem como objetivo, dentre as suas ações, atingir, no currículo da educação básica, temáticas relativas às pessoas com deficiência e desenvolver ações afirmativas que possibilitem acesso e permanência na educação superior. 
25) Em 2007, lança-se o Plano de Desenvolvimento da Educação - PDE, reafirmado pela Agenda Social, tendo como eixos a formação de professores para a educação especial, a implantação de salas de recursos multifuncionais, a acessibilidade arquitetônica dos prédios escolares, o acesso e a permanência das pessoas com deficiência na educação superior, bem como o monitoramento do acesso à escola dos favorecidos pelo Beneficio de Prestação Continuada - BPC.

26) É reafirmado no documento do MEC, Plano de Desenvolvimento da Educação: Razões, Princípios e Programas, a visão que busca superar a oposição entre educação regular e educação especial.

27) Para dar implemento ao PDE, publica-se o Decreto $n^{\circ} 6.094 / 2007$, que "estabelece nas diretrizes do Compromisso Todos pela Educação, a garantia do acesso e permanência no ensino regular e 0 atendimento às necessidades educacionais especiais dos alunos, fortalecendo seu ingresso nas escolas públicas" (p. 5).

Verifica-se que o processo de inclusão, no que se refere à documentação está bem respaldado, mas na prática, os desafios parecem gigantescos. Para Aranha (2001), o processo da inclusão escolar "prevê intervenções decisivas e incisivas, em ambos os lados da equação: no processo de desenvolvimento do sujeito e no processo de reajuste da realidade social" (p. 20).

Nesse sentido, Oliveira (2014) afirma que apesar de haver a criação de programas de incentivo à formação dos professores, como cursos de licenciatura à distância da UAB - Universidade Aberta do Brasil, por exemplo, ou bolsas de curso superior específicas para quem deseja se tornar professor, fica evidenciada a falta de uma política coordenada tanto na divulgação dos cursos quanto na efetivação de matrículas de tais profissionais. Os cursos existem, porém, os professores não são liberados de suas aulas para fazê-los. Os docentes têm que se desdobrar se quiserem estudar e nem sempre conseguem, por diferentes razões, como a longa distância entre o local de trabalho e o do curso ou a jornada exaustiva de serviço. 
No que se refere ao atendimento de alunos com TGD - Transtorno Global do Desenvolvimento nas escolas públicas de educação infantil na Asa Sul - Brasília, em sua tese de doutorado, essa autora realizou uma análise que permite concluir que

Existe um esforço pessoal das professoras de Educação Infantil na escola pública na Asa Sul - Brasília, que atuam nas classes especiais no sentido de subsidiar seu trabalho de atendimento a alunos com TGD, uma vez que essas professoras evidenciaram comprometimento com a sua formação continuada, seja através de leituras, palestras, realização de cursos e dedicação ao trabalho com o qual estão bastante comprometidas; porém, não existe, por parte do governo, a mesma disposição nessa formação de professores. Para subsidiar o trabalho de atendimento a alunos com TGD e/ou outras modalidades de ensino especial, o primeiro passo será valorizar a profissão e melhorar a formação dos professores, oferecendo cursos e condições para que os mesmos possam realizá-los.

Essa mesma autora afirma que

Embora no Distrito Federal todos os professores possuam curso superior para ingressar na Secretaria de Estado de Educação do Distrito Federal, sabe-se que os alunos que saem da faculdade com habilitação para a docência não têm recebido formação adequada, (...). Sem tal formação, os professores têm dificuldades em ensinar os alunos de maneira apropriada. Não se pode esquecer que assim como o médico precisa aprender a cuidar de um paciente para que este recupere a saúde, o professor deve aprender a dar aulas bem, para que o aluno tenha dignidade e cidadania.

Ao se realizar uma pesquisa no Google percebe-se que os cursos de licenciatura e pedagogia são encurtados, sendo muito mais baratos que outros, corroborando o descaso com que o governo trata seus professores. Ademais, a maioria dos cursos fica longe da experiência da sala de aula, cuidando apenas dos conteúdos 
disciplinares, que o professor terá de atingir em sala de aula. Este não aprende a administrar uma sala de aula na faculdade, sua experiência é cumprida nos estágios obrigatórios, os quais não são avaliados e nem programados devidamente. O estágio fica por conta do aluno, que está sujeito à boa vontade de um professor que possa recebê-lo. Não se sabe o que acontece neste estágio (OLIVEIRA, 2014).

No que diz respeito à formação continuada, a EAPE - Escola de Aperfeiçoamento de Profissionais da Educação, oferece afastamento remunerado para estudos, permitindo ao professor realizar sua especialização, mestrado ou doutorado em universidades públicas ou particulares, mas exige que o curso tenha uma grade horária de aulas semanal, o que deixa de fora, por exemplo, qualquer possibilidade de o professor realizar seu curso no exterior (OLIVEIRA, 2014).

Essa autora comenta que em recente pesquisa internacional, foi verificado que, entre 21 países, o Brasil esteve em penúltimo lugar em relação ao respeito e à valorização de seus professores. Além disso, segundo a Folha de São Paulo, o Brasil saiu-se mal no Programa Internacional de Avaliação de Estudantes - PISA, em levantamento comparativo gerado pela Organização para Cooperação e Desenvolvimento Econômico - OCDE, com o objetivo de comparar o quanto e como os países preparam os jovens para a vida produtiva.

Para essa autora, somente quando o governo,

em todos os seus níveis: municipal, estadual e federal propiciar as condições de acesso, de alfabetização e de sucesso escolar; a ampliação de recursos investidos na educação pública e a melhora da gestão de recursos; e, também, a devida e necessária valorização do magistério, o comparativo realizado pelo PISA apresentará resultados para a educação no Brasil similar aos dos países que dão prioridade à educação de seus cidadãos.

No âmbito do Distrito Federal, Mota (2012) afirma que a inclusão educacional é um conceito que ainda proporciona "diversos olhares, diversas formas de intervenção. A 
SEEDF entende que é preciso uma atenção mais apurada para as pessoas com deficiência, Transtorno Global do Desenvolvimento (TGD) e Altas Habilidades (AH)" (p. 79).

No que se refere à formação de professores, a Resolução CNE/CP ํำ1, de 18 de fevereiro de 2002, estabelece as Diretrizes Curriculares para a Formação de Professores da Educação Básica, em nível superior, curso de licenciatura de graduação plena, propondo:

Art. 2ำ A organização curricular de cada instituição observará, além do disposto nos artigos 12 e 13 da Lei 9.394, de 20 de dezembro de 1996, outras formas de orientação inerentes à formação para a atividade docente, entre as quais o preparo para:

II - o acolhimento e o trato da diversidade; (BRASIL, CNE, 2002, p.1)

§ 3ำ A definição dos conhecimentos exigidos para a constituição de competências deverá, além da formação específica relacionada às diferentes etapas da educação básica, propiciar a inserção no debate contemporâneo mais amplo, envolvendo questões culturais, sociais, econômicas e o conhecimento sobre o desenvolvimento humano e a própria docência, contemplando:

II - conhecimentos sobre crianças, adolescentes, jovens e adultos, aí incluídas as especificidades dos alunos com necessidades educacionais especiais e as das comunidades indígenas (BRASIL, CNE, 2002, p. 23).

Rodrigues (2012) acredita que estratégias como a discussão de casos e a socialização de experiências bem sucedidas no coletivo da escola podem se configurar como uma ferramenta de grande ajuda para toda a comunidade escolar. Contudo, apresenta questões que atrapalham a realização do sonho da inclusão: 
1. Nas universidades, a temática da educação das pessoas com necessidades especiais ainda não é incorporada como uma discussão geral. A formação inicial se resume a uma disciplina que não consegue atender à complexidade do tema e a formação continuada precisa ser discutida e aliada a ações de pesquisas e extensão.

2. Os alunos com necessidades especiais não são considerados, nas escolas, como alunos e sim como problemas que chegam. $O$ foco no déficit, na falta, na impossibilidade precisa ser vencido, desconstruído, para que essas pessoas assumam seus lugares de alunos, de sujeitos capazes de aprender.

3. O poder público, no âmbito federal, estadual e municipal precisa vencer a etapa das intenções e passar às ações. Investimentos nas mudanças físicas das escolas, aquisição de materiais, contratação de professores especializados e formação dos professores em serviço necessitam acontecer em caráter de urgência (p. 3).

Freire (2005) reflete sobre o trabalho desenvolvido pelo profissional da Educação Especial, ou, mais especificamente, do professor de uma pessoa com um Transtorno Invasivo do Desenvolvimento, transtorno autista, cujo desenvolvimento se encontra grandemente afetado na sua globalidade, especialmente nas áreas da interação social, da comunicação e do comportamento. Tal professor estará diante de um aluno com uma variedade de comportamentos tão incomuns, tão complexos e, quase sempre tão imprevisíveis, que inúmeras teorias e fórmulas mágicas para nada servirão, levando-o a buscar conhecimento na condição de aprendiz para poder garantir mais tarde a posição de ensinante. Trata-se de um profissional privilegiado como poucos, porque dificilmente a vida lhe oferecerá outra oportunidade como esta: tão difícil, tão assustadora, tão desafiante quanto comovedora e fascinante. Para este profissional, eis a chance de se tornar, em vários casos, o maior intermediador entre o estar aqui e o viver aqui de muitos seres humanos. 


\section{CONSIDERAÇÕES FINAIS}

Vinte e nove anos após a promulgação da Constituição Federal de 1988, verifica-se que, no dia a dia, pouco se tem feito para minimizar as condições do educando na escola e seu reajuste à realidade social. Constata-se que a contradição se instaura quando se observa o distanciamento entre os discursos e a prática, pois para cumprir os dispositivos constitucionais o MEC, representado pela Secretaria de Governo do Distrito Federal, viabiliza a matrícula ou a inclusão dos alunos com necessidades especiais mesmo sem ter a unidade escolar estrutura adequada para desenvolver o processo. Infere-se dessa assertiva que, se Estado e família atendem ao disposto na Legislação, o aluno tem assegurado seus direitos. Contudo, quando um não cumpre seu papel de promotor da educação configura-se transgressão aos princípios constitucionais.

\section{REFERÊNCIAS}

AMARAL, L. Histórias da Exclusão: e de inclusão? - na escola pública. In: Conselho Regional de Psicólogos. Educação Especial em debate. SP: Casa do Psicólogo/Conselho Regional de Psicologia, 1997.

ARANHA, Maria Salete Fábio. Educação inclusiva: v. 1: a fundamentação filosófica/coordenação geral SEESP/MEC; organização Maria Salete Fábio Aranha. Brasília: Ministério da Educação, Secretaria de Educação Especial, 2004.

Paradigmas da relação da sociedade com as pessoas com deficiência. In: Revista do Ministério Público do Trabalho. Ano XI, № 21, março, 2001.

BRASIL. Conselho Nacional de Educação. Câmara de Educação Básica. Resolução CNE/CBE no 2, de 11 de setembro de 2001, que estabelece as diretrizes nacionais para educação especial na educação básica.

BRASIL. Conselho Nacional de Educação. Resolução CNE/CP 1/2002. Brasília: Diário Oficial da União, 4 de março de 2002. Seção 1, p. 9. 
BRASIL. Constituição 1988 - Constituição da República Federativa do Brasil. São Paulo: Atlas, 1988.

BRASIL. Lei no 7.853 de 24 de outubro de 1989. Dispõe sobre o apoio às pessoas portadoras de deficiências, sua integração social, Coordenadoria Nacional para Integração da Pessoa Portadora de Deficiência - CORDE. Disponível em: $<$ http://www3.dataprev.gov.br/sislex/paginas/42/1989/7853.htm>. Acesso em: 01/01/2018.

BRASIL. Ministério da Educação. Diretrizes Nacionais Para a Educação Especial na Educação Inclusiva./Secretaria de Educação Especial. - MEC/SEESP, 2001.

BRASIL. Ministério da Educação. Secretaria de Educação Especial. Política Nacional de Educação Especial na Perspectiva da Educação Inclusiva. Brasília: MEC/SEESP, 2008

Disponível em: $<$ http://portal.mec.gov.br/arquivos/pdf/politicaeducespecial.pdf>. Acesso em: 01/01/2018.

CAMPOS, Tomaz. Secretaria de Educação é advertida por descaso em ensino especial, 10/04/2017. Disponível em: <http://www.sinprodf.org.br/secretaria-deeducacao-e-advertida-por-descaso-com-ensino-especial/>. Acesso em 01/01/2018.

FREIRE, Lucia Helena Vasconcelos. Formando professores. Transtornos invasivos do desenvolvimento: 3 milênio, 2005. Disponível em: < http://www.afaga.com.br/biblioteca/CamargosW.pdf\#page=27>. Acesso em: 01/01/2018.

MAGALHÃES, Rita de Cássia Barbosa Paiva; LIMA, Ana Paula de Holanda. Perfil de professores de educação especial: dilemas e desafios na construção da educação básica inclusiva. EccoS revista científica, jun. 2004, v. 6, № 1. Centro Universitário Nove de Julho, São Paulo, p. 85-98.

MENDES, Enicéia Gonçalves. A radicalização do debate sobre inclusão escolar no Brasil. In: Revista Brasileira de Educação, v.11, oㅜ 33, p. 387-405, dez. 2006. 
OLIVEIRA, Rita Barreto de Sales. A formação de professores e o atendimento a alunos com Transtorno Global do Desenvolvimento - TGD: o caso das escolas públicas de Educação Infantil na Asa Sul - Brasília/Tese de Doutorado, Universidad Americana - PY, 2014.

RODRIGUES, Sonia Maria. Educação inclusiva e formação docente, 2012. Diversa: educação inclusiva na prática. Disponível em: <http://diversa.org.br/artigos/artigos.php?id=1066\&/educacao_inclusiva_e_formacao _docente>. Acesso em: 01/01/2018.

Enviado: Fevereiro, 2019

Aprovado: Abril, 2019 